\title{
Seasonal acclimation of thermal performance in two species of reef-building corals
}

\author{
Saskia Jurriaans*, Mia O. Hoogenboom \\ College of Science and Engineering and ARC Centre of Excellence for Coral Reef Studies, James Cook University, Douglas, \\ Townsville QLD 4811, Australia
}

\begin{abstract}
Thermal performance curves describe the relationship between temperature and the rate of biological processes. These relationships can vary among species and environments, allowing organisms to acclimatize to their local thermal regime. This study quantified the seasonal variation in the thermal performance of several coral and symbiont-dominated physiological traits for the thermally tolerant coral species Porites cylindrica and the thermally sensitive coral species Acropora valenciennesi. Photosynthesis rates, respiration rates, maximum photosystem II (PSII) quantum yield and electron transport rates were measured in winter and summer on coral fragments exposed to an acute temperature increase and decrease up to $5^{\circ} \mathrm{C}$ above and below the average seawater temperature in each season. Results showed that colonies of A. valenciennesi acclimated primarily by shifting their optimal temperature to a higher temperature in summer, whereas colonies of $P$. cylindrica had broader thermal breadth during summer. For symbionts within both species, performance was higher at all temperatures in summer, while the thermal optima and performance breadth remained unchanged. Despite these changes in thermal performance, the thermal optima of most traits did not match the ambient environmental temperature, but fell between the summer and winter temperatures. Overall, these results showed that both coral species were physiologically plastic in response to temperature change, but that there are constraints on the rate or capacity for acclimation that prevent a perfect match between the average temperature of the environment and the thermal optimum of the species.
\end{abstract}

KEY WORDS: Climate change $\cdot$ Coral bleaching $\cdot$ Temperature stress $\cdot$ Environmental variability Performance curve $\cdot$ Photosynthesis $\cdot$ Thermal breadth

\section{INTRODUCTION}

Temperature influences the biology and ecology of all organisms, as it determines the rate of biochemical and physiological reactions. Extremely high and low temperatures are lethal and, therefore, influence the geographic limits of the distributions of species (Pörtner 2002). Within these temperature limits, however, most physiological functions, such as metabolism, locomotion and growth, perform optimally at specific temperatures (Angilletta 2009). The relationship between temperature and physio-

\footnotetext{
*Corresponding author: saskia.jurriaans@my.jcu.edu.au
}

logical functioning varies among and within species due to differences in body size, life-history traits and/or genotype-specific patterns of gene expression. For example, among 13 species of lizards, maximum sprinting speed varied when they were exposed to the same temperature, due to morphological and physiological differences (Bauwens et al. 1995). In addition, temperature is highly variable over temporal and spatial scales, meaning that physiological functions must often occur under conditions that are suboptimal for performance. To cope with this variability, organisms can adapt

๑) The authors 2020. Open Access under Creative Commons by Attribution Licence. Use, distribution and reproduction are unrestricted. Authors and original publication must be credited. 
and/or acclimate through altering their physiology and/or morphology to optimize performance in the new environment (Pörtner 2002).

Thermal sensitivity, defined as the degree to which an organism's performance depends on its temperature (Angilletta 2009), can be understood by measuring the rates of various physiological functions over a temperature gradient, usually in the form of a thermal performance curve (TPC) (Huey \& Stevenson 1979). Typically, TPCs capture the rate of increase of performance as temperature begins to increase, the maximum performance $\left(\mathrm{Pf}_{\max }\right)$ which occurs at the optimal temperature $\left(T_{\mathrm{opt}}\right)$, and the decline in performance at temperatures above the optimum. The breadth of the curve ( $\left.T_{\mathrm{br}}\right)$ encompasses the temperature range at which performance is positive. The height and breadth of the TPC (as determined by $\mathrm{Pf}_{\max }$ and $T_{\text {br }}$ ) and the position of the TPC along a temperature gradient (as determined by $T_{\text {opt }}$ ) varies between species from different thermal environments. For example, when comparing the jumping performance of frog populations (Limnodynastes peronii) from different latitudes, $T_{\text {opt }}$ increased with increasing environmental temperature because populations from cooler climates performed better at cooler temperatures and vice versa (Wilson 2001). Similarly, Tagliarolo \& McQuaid (2015) showed that physiological adaptations determined the distribution of mussels, with the eastern lineage of Perna perna better adapted to warm temperatures and Mytilus galloprovincialis better adapted to cool temperatures. The capacity to change the shape and position of the TPC depends on the phenotypic plasticity of the organism, defined as the ability of a genotype to express different phenotypes of a trait when exposed to changes in environmental conditions (Whitman \& Agrawal 2009). Phenotypic plasticity is influenced by the variability and predictability of the thermal environment, and the time required to adjust to the new environment (Gabriel 2005). Therefore, $T_{\text {opt }}$ is likely to be a compromise between the past, current and future environments. Moreover, if the time required for acclimation to a new environment exceeds the time spent in the new environment (e.g. an organism requires more time to adjust its performance to correspond to winter temperatures than the actual duration of winter), $T_{\text {opt }}$ will be closer to the future temperature (e.g. summer temperature). In addition, $T_{\mathrm{br}}$ is likely to vary depending on the predictability of the environmental fluctuations such that if environmental stochasticity increases, $T_{\mathrm{br}}$ should also increase (Gabriel 2005). While these concepts can explain why certain species show a mis- match between the environmental temperature and their $T_{\text {opt, }}$ few empirical studies tested these predictions directly.

Coral reef ecosystems are particularly vulnerable to rising sea surface temperatures associated with climate change (Pörtner et al. 2014). Reef-building corals live within a relatively narrow temperature range close to their upper thermal threshold (Jokiel \& Coles 1990, Berkelmans \& Willis 1999). Heat stress is linked to coral bleaching (Brown 1997), a process that disrupts the relationship between the coral host and its algal symbiont (Symbiodinium spp.) and can lead to coral mortality. However, the response to heat stress differs among coral species (e.g. Loya et al. 2001), and some have been found to enhance heat tolerance via physiological acclimation (Coles \& Brown 2003, Oliver \& Palumbi 2011), genetic adaptation of the coral host (Howells et al. 2016) and symbionts (Csaszar et al. 2010, Howells et al. 2012), as well as changes in Symbiodinium (Berkelmans \& Van Oppen 2006, Silverstein et al. 2015). However, increased heat tolerance of coral-algal symbioses can result in cold intolerance (Howells et al. 2013). This means that physiological acclimation to summer warming needs to be reversed during winter in order to maintain the fitness of coral colonies and populations. Depending on the duration and temperature range experienced during different seasons, adopting the 'wrong' thermal strategy will have consequences for the productivity and survival of coral reefs. Hence, understanding plasticity of coral thermal performance provides insight as to whether or how corals can adapt and acclimatize to global warming (Logan et al. 2014).

On coral reefs, temperatures naturally vary over seasonal and diurnal cycles. At present, however, it is unknown whether corals cope with these temperature fluctuations via high thermal plasticity by varying $T_{\text {opt }}$ to correspond to the summer and winter temperature, or via broad thermal tolerance that includes all temperatures encountered throughout the year. The use of TPCs to assess variability in thermal tolerance is slowly gaining in popularity in coral science. For instance, TPCs assessing the thermal variability among locations demonstrated geographic variation in $T_{\text {opt }}$ among coral populations for several metabolic processes, such as photosynthesis, respiration (Aichelman et al. 2019, Jurriaans \& Hoogenboom 2019) and calcification (Sawall et al. 2015), although this effect was not observed among certain temperate coral populations (Rodolfo-Metalpa et al. 2014). In addition, over the course of a year, the photosynthesis, respiration and calcification rates of 4 Caribbean 
reef corals were higher in summer than in winter, but $T_{\text {opt }}$ was consistent between seasons, demonstrating that the TPC of these corals only shifted vertically between seasons (Scheufen et al. 2017b). In contrast, certain Indo-Pacific coral species increased the upper thermal threshold in summer (Berkelmans \& Willis 1999), demonstrating that the thermal sensitivity of corals can change between seasons, although this does not reveal whether it is the shape or position of the TPC, or a combination of both, that varies between seasons.

In addition to variability in temperature, the light environment also fluctuates among seasons. Photoacclimation to light can be regulated by the holobiont through uptake or expulsion of symbionts, and by the symbiont by controlling the photochemistry of photosystem II (PSII). For instance, the minimum saturating irradiance $\left(E_{k}\right)$ in corals was 2-fold higher in spring when the overall irradiance was higher compared to summer (Nitschke et al. 2018). Moreover, light availability can influence the productivity of corals, but also their response to thermal stress (Robison \& Warner 2006, Ulstrup et al. 2008). For instance, in summer, higher irradiance levels and warmer waters lead to decreased chlorophyll and symbiont concentrations (Winters et al. 2009), and reduced maximum photochemical yield of PSII (Warner et al. 2002, Ulstrup et al. 2008). Therefore, when comparing coral TPC between seasons, the seasonal variability of the light environment needs to be considered.

This study aimed to quantify the coral TPC in summer and winter to determine how corals use thermal plasticity to cope with seasonal differences in temperature. We assessed whether the shape (thermal breadth and maximum performance) and the position (optimal temperature) changed between seasons, and whether coral performance was optimal in each season. In addition, we assessed whether plasticity in the shape and position of the TPC was speciesspecific by comparing a thermally tolerant coral species with a thermally sensitive one. We hypothesized that the thermally tolerant species would have a higher upper thermal threshold than the thermally sensitive species due to a wider thermal breadth. As thermal sensitivity is variable within a species, we additionally compared performance curves between colonies for within-population (i.e. among genotype) variation. Finally, to investigate whether variation in the thermal performance was due to plasticity of the coral or the symbiont, we measured performance traits dominated by the coral and symbiont physiology specifically.

\section{MATERIALS AND METHODS}

\subsection{Experimental design}

The physiological performance of 2 stony coral species was assessed over a range of temperatures in both summer and winter to determine whether their TPCs were fixed or plastic, and whether plasticity of the TPC could benefit corals by matching their optimal temperature for performance to the seasonal average temperature. Winter thermal performance was measured during the last week of August and first week of September 2015 (austral winter). Summer thermal performance was measured during the last 2 wk of January 2016 (austral summer). Fragments of Acropora valenciennesi and Porites cylindrica were collected from a consistent depth at several sites around the Palm Islands, central Great Barrier Reef, in April 2015. The species were chosen for their abundance throughout the Great Barrier Reef, but also for their contrasting thermal sensitivity, with $A$. valenciennesi being more bleaching-susceptible than P. cylindrica (Loya et al. 2001, Visram \& Douglas 2007). Previous studies show that A. valenciennesi commonly harbours Cladocopium C3 (formerly, Clade C sub-clade C3) and P. cylindrica harbours Cladocopium C15 (formerly, Clade C sub-clade C15) (LaJeunesse et al. 2003, Madin et al. 2016, LaJeunesse et al. 2018). Between these 2 Cladocopium species, C3 is more sensitive to heating than C15 (Fisher et al. 2012). Therefore, differences in the shape and position of the performance curves between species and seasons were expected. A total of 80 fragments of each species, each $\sim 8 \mathrm{~cm}$ diameter, 5 per colony, were collected at depths between 4 and $6 \mathrm{~m}$ depending on the tide. Care was taken to select fragments with comparable light exposure by selecting branches that were positioned upright, situated at the upper edge of the colonies. Fragments were transported to Orpheus Island Research Station, Palm Islands, Great Barrier Reef, attached to nylon string in upright position allowing each fragment to receive equal amounts of light, labelled by source colony identity, and placed in a large (1500 l) outdoor aquarium ('raceway'). Due to unexpected high mortality in mid-September, caused by several days of abnormally low temperatures $\left(<20^{\circ} \mathrm{C}\right.$ in the raceway, see Fig. 1), 40 additional fragments of $A$. valenciennesi were collected in November 2015 and 20 additional fragments of $P$. cylindrica in December 2015. For the summer thermal experiment, we used the newly collected fragments to ensure similar thermal histories among individuals. 


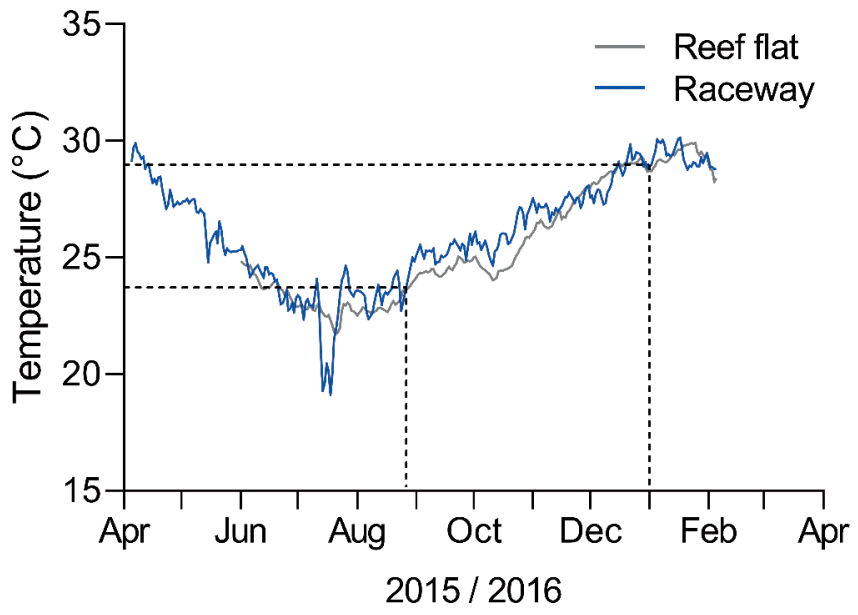

Fig. 1. Mean daily temperature variation measured at the sampling site on the reef flat at $5.8 \mathrm{~m}$ depth and in the raceway. Dashed lines: temperature at the start of the winter (late August $2015,24^{\circ} \mathrm{C}$ ) and summer (January 2016, 29 ${ }^{\circ} \mathrm{C}$ ) thermal experiments. Seawater temperature data recorded by in situ data loggers of the Australian Institute of Marine Science (AIMS 2017)

\subsection{Raceway conditions}

The raceway was supplied with seawater pumped from the reef slope in front of the station with a flowthrough rate of approximately $250 \mathrm{l} \mathrm{h}^{-1}$. Shading was provided using a mesh shade cloth to acquire light levels similar to the in situ reef environment at the collection depth. Water temperature and light levels in the raceway varied naturally according to the local environmental conditions on the reef (see Fig. 1; Fig. S1 in the Supplement at www.int-res.com/ articles/suppl/m635p055_supp.pdf). Temperature was recorded with a HOBO data logger (Onset Computer Corporation) set to a $1 \mathrm{~h}$ interval. Irradiance levels in the raceway were measured every hour from dawn to dusk on 2 random days each month using a LI-193 spherical underwater quantum sensor (LI-COR). Daily irradiance light levels averaged $284 \mu \mathrm{mol} \mathrm{m}{ }^{-2} \mathrm{~s}^{-1}$ in summer and $133 \mu \mathrm{mol} \mathrm{m}{ }^{-2} \mathrm{~s}^{-1}$ in winter (Table S1 in the Supplement). During the summer months, starting in December 2015, 2 chiller/heater units (TK-2000, TECO) were placed next to the raceway to prevent water temperature from increasing above $31^{\circ} \mathrm{C}( \pm$ $0.5^{\circ} \mathrm{C}$ ) which could occur at the research station as seawater was pumped across the shallow reef flat and held temporarily in large storage tanks. During these months, the water flowthrough rate was also increased to $500 \mathrm{l} \mathrm{h}^{-1}$ to help maintain a consistent water temperature. It was assumed that the seawater supplied adequate nutrition for the coral fragments, but every 2 wk, additional Artemia nauplii was given as a sup- plementary food source. Every month, the raceway and fragments were cleaned to minimize algal proliferation. Temperature in the raceway was compared with the ambient temperature on the reef slope at 5.8 $\mathrm{m}$ depth (Orpheus Island Relay Pole 1) measured by temperature loggers of the Australian Institute of Marine Science (AIMS 2017).

\subsection{Experimental conditions}

To quantify seasonal variation in thermal performance, 25 fragments of each species, 5 fragments from each of 5 colonies, were selected from the raceway and distributed between 2 additional tanks (50 l each) placed directly adjacent to the raceway. This design enabled manipulation of water temperature for thermal performance measurements without any change in the light environment to which the corals were naturally acclimated. The same water was supplied to the smaller tanks and the raceway, except that the flowrate in the $50 \mathrm{l}$ tanks was lowered to $36 \mathrm{l} \mathrm{h}^{-1}$ to facilitate experimental temperature manipulation. The corals were maintained at ambient temperature in the $50 \mathrm{ltanks}$ for $1 \mathrm{wk}$ of acclimation before starting with the measurements. Temperature in each tank was recorded using $\mathrm{HOBO}$ data loggers. After measuring the response variables (see Section 2.4) at ambient temperature, 1 fragment of each colony was frozen at $-80^{\circ} \mathrm{C}(\mathrm{n}=5$ per species) for later tissue analyses. Subsequently, the water temperature in one $50 \mathrm{l}$ tank was progressively increased while the water temperature in the other $50 \mathrm{l}$ tank was progressively decreased (Fig. S2 in the Supplement) using a chiller/ heater unit (TK-2000) connected to a pump (Aquapro AP1050, Aquatec) that circulated the water through the temperature control unit at a rate of $500 \mathrm{l} \mathrm{h}^{-1}$. Every morning, the water temperature was increased or decreased by $0.5^{\circ} \mathrm{C}$ over the course of $10 \mathrm{~d}$, until the 501 tanks reached either $5^{\circ} \mathrm{C}$ above or below ambient temperature. At every $1^{\circ} \mathrm{C}$ increment, 5 physiological response variables (see Section 2.4) were measured. At the end of the thermal experiment, fragments were frozen at $-80^{\circ} \mathrm{C}$ and transported, frozen on dry ice, to laboratory facilities at James Cook University for tissue analyses.

\subsection{Response variables}

Although the coral holobiont is a symbiosis between the coral host and the symbiont, the thermal response of the symbiont might differ from that of the 
holobiont (colony). Therefore, net photosynthesis rates and respiration rates (predominantly a coral host response) were measured using oxygen respirometry to provide information about the plasticity of the TPC of the holobiont, and maximum PSII quantum yield and electron transport rate (predominantly a symbiont response) were measured to provide information about the plasticity of the TPC of the symbiont. In addition, the light saturation parameter $\left(E_{k}\right)$ was calculated to capture possible photoacclimation between summer and winter.

\subsubsection{Holobiont response variables}

For each coral fragment, rates of net photosynthesis $\left(P_{\text {net }}\right)$ and respiration $(R)$ were measured in transparent experimental cells ( 6 cells, $\sim 550 \mathrm{ml}$ ) for $1 \mathrm{~h}$. Five cells were filled with filtered seawater $(15 \mu \mathrm{m})$ in which a coral fragment was suspended and 1 cell contained only seawater to control for background respiration. The cells were placed in a water bath connected to a chiller/heater unit (TK-2000) to control the water temperature inside the cells (corresponding to the treatment temperature of that day). During $1 \mathrm{~h}$, the dissolved oxygen concentration inside each cell was measured using oxygen probes (LDO101, Hach) connected to a meter device (HQ40D, Hach) at 1 min intervals. The cells were placed on a submersible magnetic stirrer plate (MIXdrive 6, 2mag) and a magnetic stirrer bar inside each cell ensured continued mixing of the water. $P_{\text {net }}$ rates were measured at a light intensity of $350 \mu \mathrm{mol}$ photons $\mathrm{m}^{-2} \mathrm{~s}^{-1}$ provided by 2 wide beam lamps (Oracle) with $150 \mathrm{~W}$ metal halide light. This irradiance level is within the range experienced by the fragments in the raceway and in situ on the reef flat (Fig. S1). $R$ rates were measured in the dark directly after the photosynthesis measurements. At the end of the respirometry measurements, corals were returned to their experimental tanks (50 1 tanks, see Section 2.3). $P_{\text {net }}$ and $R$ rates of each coral were corrected by subtracting the differential oxygen concentration of the empty control cell and multiplying by the net water volume of the cell, which was measured for each cell after every respirometry measurement and accounted for the displacement volume of the coral fragment, oxygen probe and magnetic stirrer.

\subsubsection{Symbiont response variables}

At the end of the dark respiration measurement, the maximum quantum yield $\left(F_{\mathrm{v}} / F_{\mathrm{m}}\right)$ of PSII of each frag- ment was measured using a pulse-amplitude modulated (PAM) fluorometer (DIVING-PAM, Walz). $F_{\mathrm{v}} / F_{\mathrm{m}}$ describes the proportion of light energy used for photochemistry by the (dark-adapted) symbionts. On dark-adapted fragments, chlorophyll fluorescence was measured using a fiberoptic probe kept at a fixed distance $(3 \mathrm{~mm})$ from the coral surface by a flexible piece of tubing placed around the probe tip. First, the minimal fluorescence $\left(F_{0}\right)$ was measured by applying a weak light pulse $\left(<1 \mathrm{~mol}\right.$ photon $\left.\mathrm{m}^{-2} \mathrm{~s}^{-1}\right)$ that did not induce photosynthesis and determined the proportion of open reaction centres of PSII. Subsequently, the maximum fluorescence $\left(F_{\mathrm{m}}\right)$ was measured by applying a saturating light pulse $\left(>5000 \mu \mathrm{mol}\right.$ photons $\mathrm{m}^{-2}$ $\mathrm{s}^{-1}$ ) that closed all PSII reaction centres and resulted in a greater fluorescence emission. $F_{\mathrm{v}} / F_{\mathrm{m}}$ was calculated as $\left[F_{\mathrm{m}}-F_{0}\right] / F_{\mathrm{m}}$ (Schreiber 2004). Five measurements, evenly distributed over the coral surface, were made on each coral fragment, of which an average $F_{\mathrm{v}} / F_{\mathrm{m}}$ was taken. Corals were assumed dark-adapted after $40 \mathrm{~min}$ in darkness (Hoegh-Guldberg \& Jones 1999) and $F_{\mathrm{v}} / F_{\mathrm{m}}$ was measured around the same time in the morning and afternoon each day.

Immediately after the light photosynthesis measurement, rapid light curves (RLCs) were measured on the light-adapted fragments using the DIVINGPAM. RLCs provide information on the saturation characteristics of PSII electron transport (Ralph \& Gademann 2005) and were used to assess the photosynthetic capacity of PSII as a function of instantaneous irradiance under different temperatures. A standardized procedure was used to measure the RLCs across all experimental fragments to reliably compare the relative electron transport rate (rETR) among experimental fragments. RLCs were measured using an internal program of the DIVING-PAM that provided a sequence of 9 actinic light steps, with light intensities increasing from 5 to $1800 \mu \mathrm{mol}$ photons $\mathrm{m}^{-2} \mathrm{~s}^{-1}$. Each illumination period lasted $10 \mathrm{~s}$ and finished with a saturating pulse after each step that measured the effective PSII quantum yield $\left(\Delta F / F_{\mathrm{m}}{ }^{\prime}\right)$, calculated as $\left[F_{\mathrm{m}}{ }^{\prime}-F\right] / F_{\mathrm{m}}{ }^{\prime}$, where $F_{\mathrm{m}}{ }^{\prime}$ is the maximum fluorescence of the light-adapted sample and $F$ is the instant fluorescence emission. The rETR was then calculated as:

$$
\mathrm{rETR}=\Delta F / F_{\mathrm{m}}{ }^{\prime} \times \mathrm{PAR} \times 0.5
$$

where PAR was the photosynthetically active radiation and the 0.5 corrected for 2 photons of light required for the transport of 1 electron. RLCs were then created by plotting rETR against instant irradiance, and curves were fitted following the model of Platt et al. (1980): 
$\mathrm{rETR}=\mathrm{Ps} \times[1-\exp (-\alpha \times E / \mathrm{Ps}) \times \exp (-\beta \times E / \mathrm{Ps})]$

where Ps was a scaling factor that represents the potential maximum $\mathrm{rETR}_{\mathrm{m}}$, $\alpha$ the initial slope of the RLC before the onset of saturation, $E$ the irradiance emitted by the DIVING-PAM, and $\beta$ the slope of the RLC where PSII declines. From this, $\mathrm{rETR}_{\mathrm{m}}$ and $E_{k}$ were estimated following the equations described by Ralph \& Gademann (2005):

$$
\begin{gathered}
\operatorname{rETR}_{\mathrm{m}}=\operatorname{Ps}(\alpha /[\alpha+\beta]) \times(\beta /[\alpha+\beta])^{\beta / \alpha} \\
E_{k}=\mathrm{rETR}_{\mathrm{m}} / \alpha
\end{gathered}
$$

\subsection{Chlorophyll concentration}

Chlorophyll concentrations were determined for control fragments that were frozen at the start of the experiment at ambient temperature (ambient group, $\mathrm{n}=5$ ), and for fragments that were frozen at the end of the experiment after exposure to $5^{\circ} \mathrm{C}$ above or below ambient temperature (consecutively, heated and chilled group, $\mathrm{n}=10$ per group). Coral tissue was removed from the skeleton using an airbrush and $15 \mathrm{ml}$ filtered $(1 \mu \mathrm{m})$ seawater. The tissue slurry was homogenized using a homogenizer ( $T 25$ UltraTurrax, IKA), after which $5 \mathrm{ml}$ was centrifuged (Rotina 380R, Hettich Lab Technology) for $10 \mathrm{~min}$ at $5000 \times g$. The supernatant was discarded and $5 \mathrm{ml}$ of $90 \%$ acetone was added to the pellet and left at $4{ }^{\circ} \mathrm{C}$ in darkness for $24 \mathrm{~h}$ to extract the chlorophyll. The extract was then centrifuged once more for $10 \mathrm{~min}$ at $5000 \times \mathrm{g}$, after which $200 \mu \mathrm{l}$ of the supernatant was added in triplicates to a multiwell plate. Absorbance was measured at 630, 663 and $750 \mathrm{~nm}$ using a spectrophotometer (Spectramax M2 Reader, Molecular Devices). Chl $a$ and $c_{2}$ concentrations were calculated using the equations of Jeffrey \& Humphrey (1975).

\subsection{Data normalization}

To allow for comparison between fragments, the respirometry rates and chlorophyll concentrations were normalized by coral skeletal surface area. Coral skeletal surface area was determined following the single wax dipping method described by Veal et al. (2010). Briefly, the weight of the coral skeleton was recorded before and after being dipped in melted paraffin. The mass increase of the coated skeleton was calibrated to surface area using a standardized curve, which was plotted as the surface area versus mass increments of wooden cylinders of varying sizes.

\subsection{Data analyses}

Data were analysed using the statistical software $\mathrm{R}$ version 3.0.3 (R Foundation for Statistical Computing) and graphed with Prism GraphPad Software version 7.03 .

To assess whether the temperature response of $P$. cylindrica and A. valenciennesi varied between seasons and species, non-linear least-squares regression models were fitted to the variables $P_{\text {net, }} \mathrm{rETR}_{\mathrm{m}}$, $F_{\mathrm{v}} / F_{\mathrm{m}}$ and $E_{\mathrm{k}}$. The following Gaussian function (Rodolfo Metalpa et al. 2014) was used to fit to the data:

$$
P=\mathrm{Pf}_{\max } \exp \left\{-0.5\left(\left[\operatorname{abs}\left(T-T_{\mathrm{opt}}\right)\right] / T_{\mathrm{br}}\right)^{2}\right\}
$$

where $P$ is the temperature $(T)$-dependent physiological response, $\mathrm{Pf}_{\max }$ is the maximum value of that response, $T_{\mathrm{opt}}$ is the temperature at which the response value is optimal (i.e. the mean value) and $T_{\mathrm{br}}$ is the breadth of the response curve (i.e. the standard deviation). For each response variable, the function was first fitted to all the data pooled together regardless of season and species, and then fitted to the data separated by either species or season, and finally fitted to the data separated by both species and season. The Akaike information criterion (AIC) test was used to identify the model that was best supported by the data, which was the one with the lowest AIC value. Parameter estimates $\left(\mathrm{Pf}_{\max }, T_{\mathrm{opt}}\right.$ and $T_{\text {br }}$ ) were calculated as the average of the colony responses for each species per season. Simple Welch $t$-tests were used to detect differences in the parameter estimations between seasons that could indicate reversible acclimation. Results were considered significant when $\mathrm{p}<0.05$.

Respiration data were grouped by species and season and examined by linear regression with temperature as covariate. Since the parameters $\mathrm{Pf}_{\max }, T_{\mathrm{opt}}$ and $T_{\text {br }}$ could not be calculated as with non-linear regression, thermal sensitivity was measured using the temperature coefficient $Q_{10}$. In this study, $Q_{10}$ was calculated as

$$
Q_{10}=\left(R_{2} / R_{1}\right) \exp 10 /\left(T_{2}-T_{1}\right)
$$

where $Q_{10}$ is the ratio of the respiration rates $R_{1}$ and $\mathrm{R}_{2}$ measured at temperatures $T_{1}$ and $T_{2} . Q_{10}$ is typically around 2 for physiological processes (Withers 1992), and a lower $Q_{10}$ indicates that respiration rates 
were less sensitive to increasing temperatures, whereas a higher $\mathrm{Q}_{10}$ indicates higher thermal sensitivity. In addition, a linear mixed-effect ANOVA was used ('lme4' package), with species and season as independent variables, temperature as the covariate and colony as random effect, to test whether the effect of temperature on the respiration rates differed between the seasons or between species. For this analysis, data were log-transformed to meet the assumptions of homogeneity of variance and normality of the residuals. Similar to the model selection procedure for the non-linear regression, factors were sequentially added to the linear model and the fit of the model to the data was compared. To do so, the effect of temperature as the only predictor for the respiration rates was estimated first, then species or season were added as main effects in the model and finally the interaction of species and season with temperature was added. For consistency with the non-linear regression model selection procedure, AIC values were calculated and assessed at each step of the model as well to see if the added variable improved the overall fit of the model to the data. In a similar fashion, it was assessed whether colony as random effect improved the model fit.

Chlorophyll data were tested for assumptions of normality (Shapiro-Wilk test, p > 0.05) and homogeneity of variance (Levene's test, p > 0.05) and logtransformed when assumptions were not met (chlorophyll data for $P$. cylindrica). To account for repeated measures of fragments from the same colonies, data were analysed using mixed-effects ANOVAs per species with treatment (heated and chilled) and season as fixed effect and colony as random effect, to detect variation in mean chlorophyll concentrations between treatments and season. Chlorophyll concentrations of the fragments collected at the start of the experiment at ambient temperature were assessed separately, using a 2-way ANOVA with species and season as fixed effect, to detect differences in the chlorophyll concentration in summer and winter and across species.

All data are average $\pm \mathrm{SD}$, unless reported otherwise.

\section{RESULTS}

\subsection{Seasonal variation in temperature}

The seawater temperature in the raceway followed the seasonal trend of the seawater temperature in situ (Fig. 1). The lowest recorded temperature was in
July (19.1 and $21.7^{\circ} \mathrm{C}$ in the raceway and on the reef slope, respectively) and the highest in January (30.1 and $29.9^{\circ} \mathrm{C}$ in the raceway and on the reef slope, respectively). Mean (winter) seawater temperature in the raceway during the last $2 \mathrm{wk}$ of August was $23.9 \pm 0.7^{\circ} \mathrm{C}$; hence $24^{\circ} \mathrm{C}$ was set as ambient temperature during the winter thermal experiment. Mean (summer) seawater temperature in the raceway during the last 2 wk of January was $29.3 \pm 0.4^{\circ} \mathrm{C}$, therefore the ambient temperature during the summer thermal experiment was set at $29^{\circ} \mathrm{C}$.

\subsection{Holobiont response}

Photosynthesis $\left(P_{\text {net }}\right)$ rate showed an approximately symmetrical Gaussian relationship with temperature (Fig. 2a,b), whereas respiration $(\mathrm{R})$ rates increased linearly with temperature (Fig. 2c,d). There was strong model support for seasonal and among-species variation (Table 1; Table S2 in the Supplement) for all of the measured response variables, indicating that the thermal performance varied between species and season.

The optimal temperature for Pnet of Acropora valenciennesi corresponded to the environmental temperature in winter ( $T_{\text {opt }}$ of $24.4 \pm 0.4^{\circ} \mathrm{C}_{i}$ Fig. 2a, Table 2), and significantly increased in summer (Welch $t$-test, $\mathrm{p}=0.002$; Table 3 ) but remained below the ambient temperature in summer $\left(T_{\text {opt }}\right.$ of $27.9 \pm$ $\left.1.5^{\circ} \mathrm{C}\right)$. However, in summer, the breadth of the curve became wider $\left(T_{\mathrm{br}}\right.$ of $7.1 \pm 1.7$ and $10.5 \pm 0.8^{\circ} \mathrm{C}$ in winter and summer, respectively), which coincided with a significant decrease in the maximum net photosynthetic rate $\left(\mathrm{Pf}_{\max }\right.$ of $0.51 \pm 0.04$ versus $0.30 \pm 0.06$ $\mu \mathrm{mol} \mathrm{O}_{2} \mathrm{~cm}^{-2} \mathrm{~h}^{-1}$ in winter and summer, respectively). For Porites cylindrica, the optimal temperature for $P_{\text {net }}$ was similar between seasons (Welch $t$-test, $\mathrm{p}=0.414$; Table 3 ), which was below the ambient temperature ( $T_{\text {opt }}$ of $21.4 \pm 2.4$ and $22.8 \pm 3.3^{\circ} \mathrm{C}$ in winter and summer respectively; Fig. 2b, Table 2). Similar to A. valenciennesi, the breadth of the curve significantly increased in summer $\left(T_{\mathrm{br}}\right.$ of $12.2 \pm 3.5$ and $18.5 \pm 4.7^{\circ} \mathrm{C}$ in winter and summer, respectively), and the maximum $P_{\text {net }}$ rate decreased $\left(\mathrm{Pf}_{\max }\right.$ of $0.41 \pm$ $0.06 \mu \mathrm{mol} \mathrm{O}_{2} \mathrm{~cm}^{-2} \mathrm{~h}^{-1}$ in winter and $0.25 \pm 0.02 \mu \mathrm{mol}$ $\mathrm{O}_{2} \mathrm{~cm}^{-2} \mathrm{~h}^{-1}$ in summer). Between species, the maximum $P_{\text {net }}$ rate of $A$. valenciennesi in winter was significantly higher than that of $P$. cylindrica, but this difference was not apparent in summer.

Regarding $R$, including colony as a random effect improved the fit of the linear model (Table S3 in the Supplement). There was a positive linear relation- 


\section{A. valenciennesi}
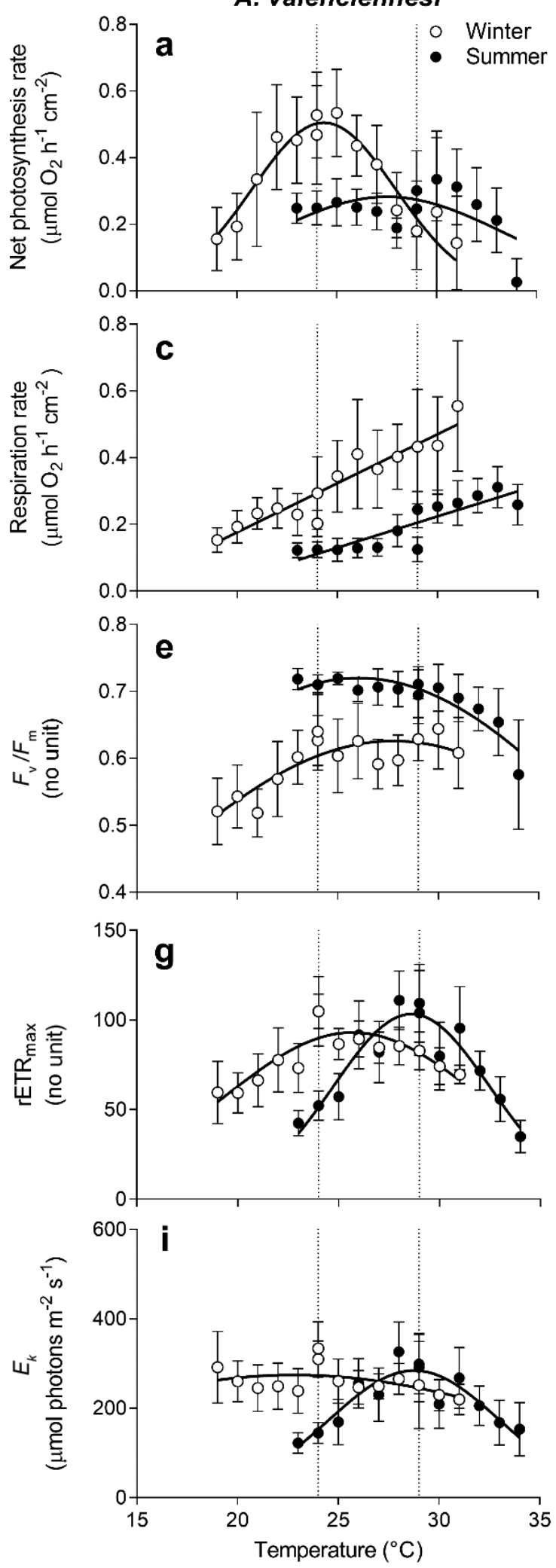

P. cylindrica
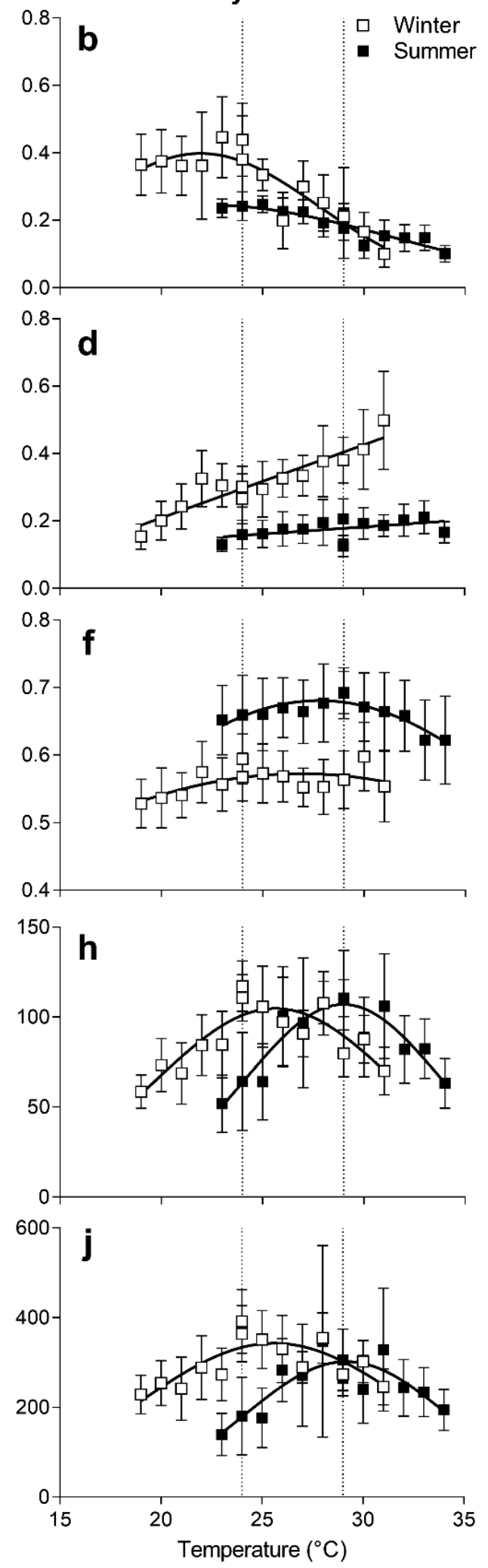

Fig. 2. Thermal performance curves of $(a, b)$ net photosynthesis rate, $(c, d)$ respiration rate, $\left(e_{,}, f\right)$ maximum PSII quantum yield $\left(F_{\mathrm{v}} / F_{\mathrm{m}}\right),(\mathrm{g}, \mathrm{h})$ maximum electron transport rate $\left(\mathrm{rETR}_{\mathrm{m}}\right)$ and $(\mathrm{i}, \mathrm{j})$ light saturation coefficient $\left(E_{\mathrm{k}}\right)$ measured on Acropora valenciennesi (left panels) and Porites cylindrica (right panels) during summer and winter. Points are mean $\pm \mathrm{SD}, \mathrm{n}=10$. Vertical dotted lines: environmental winter and summer temperature. Curves fitted using least-squares non-linear regressions for all variables except respiration rate, which are linear regressions 
Table 1. Comparison of thermal performance curves with different combinations of data selection for different physiological responses. Non-linear regression models were fitted to the data for net photosynthesis rate $\left(P_{\text {net }}\right)$, maximum PSII quantum yield $\left(F_{\mathrm{v}} / F_{\mathrm{m}}\right)$ and maximum electron transport rate $\left(\mathrm{rETR}_{\mathrm{m}}\right)$; mixed linear regression models were fitted to the data for respiration rate $(R)$. $K$ : number of estimated parameters in the model; $\Delta$ AIC: difference between the Akaike information criterion (AIC) value of the model and the minimum AIC value among all the models of the thermal response; AIC weight: weighted average of the model and represents the relative likelihood

\begin{tabular}{|lccccc|}
\hline $\begin{array}{c}\text { Thermal } \\
\text { response }\end{array}$ & Data selection & $K$ & $\begin{array}{c}\text { Cumulative } \\
\text { AIC }\end{array}$ & AIC & $\begin{array}{c}\text { AIC } \\
\text { weight }\end{array}$ \\
\hline$P_{\text {net }}$ & All data & 4 & -699.95 & 419.34 & $<0.0001$ \\
& Season & 4 & -901.03 & 218.26 & $<0.0001$ \\
& Species & 4 & -821.19 & 298.10 & $<0.0001$ \\
& Season $\times$ Species & 4 & -1119.30 & 0.00 & $\sim 1.00$ \\
$R$ & All data & 4 & 561.20 & -1114.40 & $<0.0001$ \\
& Season & 6 & 601.74 & -1191.48 & $<0.0001$ \\
& Species & 6 & 575.64 & -1139.28 & $<0.0001$ \\
& Season $\times$ Species & 10 & 622.11 & -1224.22 & $\sim 1.00$ \\
$F_{\mathrm{v}} / F_{\mathrm{m}}$ & All data & 4 & -1387.04 & 373.94 & $<0.0001$ \\
& Season & 4 & -1682.97 & 78.01 & $<0.0001$ \\
& Species & 4 & -1424.96 & 336.02 & $<0.0001$ \\
& Season $\times$ Species & 4 & -1760.98 & 0.00 & $\sim 1.00$ \\
$\mathrm{rETR}_{\mathrm{m}}$ & All data & 4 & 4717.40 & 272.35 & $<0.0001$ \\
& Season & 4 & 4518.66 & 73.61 & $<0.0001$ \\
& Species & 4 & 4685.19 & 240.14 & $<0.0001$ \\
& Season $\times$ Species & 4 & 4445.05 & 0.00 & $\sim 1.00$ \\
\hline
\end{tabular}

ship between temperature and $R$ of both species (Fig. 2c, d; mixed-effects ANOVA, effect of temperature, $\left.F_{1,513}=336.57, \mathrm{p}<0.001\right)$. In both seasons, the temperature at which the $\mathrm{R}$ rate was the lowest corresponded to the lowest experimental temperature, which was $19^{\circ} \mathrm{C}$ in winter and $23^{\circ} \mathrm{C}$ in summer. The effect of temperature on $R$ was stronger in winter than in summer (mixed-effects ANOVA, interaction between temperature and season, $F_{1,513}=55.63, \mathrm{p}<0.001$ ), which was also evident by higher $Q_{10}$ values in winter $(3.4 \pm 1.8$ for $A$. valenciennesi and $2.1 \pm 0.9$ for $P$. cylindrica; Table 2) than in summer $(2.7 \pm 1.0$ for $A$. valenciennesi and $1.6 \pm 0.3$ for P. cylindrica). Consequently, there was a significant effect of temperature on $\mathrm{R}$ in summer for $A$. valenciennesi $\left(Q_{10}>\right.$ 2.0), while for $P$. cylindrica, this effect was not apparent, which might be related to the wide thermal breadth of $P_{\text {net }}$ in summer (Fig. 2b).

\subsection{Symbiont response}

The symbiont response variables, maximum PSII quantum yield $\left(F_{\mathrm{v}} / F_{\mathrm{m}}\right)$ and maximum electron transport rate $\left(\mathrm{rETR}_{\mathrm{m}}\right)$, showed a Gaussian relationship with temperature (Fig. 2e-h). Furthermore, similar to the response variables at the holobiont level, there was strong model support for seasonal and among-species variation (Table 1, Table S2).

The performance curves for $F_{\mathrm{v}} / F_{\mathrm{m}}$ of both species responded in similar fashion to the seasonal environmental temperature (Fig. 2.e-f): $\mathrm{Pf}_{\max }$ increased in

Table 2. Mean $\pm \mathrm{SD}$ of the parameter estimates for net photosynthesis rate $\left(P_{\mathrm{net}}\right)$, maximum PSII quantum yield $\left(F_{\mathrm{v}} / F_{\mathrm{m}}\right)$, maximum electron transport rate $\left(\mathrm{rETR}_{\mathrm{m}}\right)$ and minimum light saturation $\left(E_{\mathrm{k}}\right)$ of Acropora valenciennesi and Porites cylindrica. For respiration rate $(R)$, the temperature coefficient $Q_{10}$ was calculated as an estimate for thermal sensitivity. Pf max: maximum performance; $T_{\mathrm{br}}$ : breadth of the curve; $T_{\mathrm{opt}}$ : optimal temperature

\begin{tabular}{|c|c|c|c|c|c|}
\hline \multirow{2}{*}{$\begin{array}{l}\text { Thermal } \\
\text { response }\end{array}$} & \multirow{2}{*}{$\begin{array}{l}\text { Parameter } \\
\text { estimate }\end{array}$} & \multicolumn{2}{|c|}{ A. valenciennesi } & \multicolumn{2}{|c|}{ P. cylindrica } \\
\hline & & Winter & Summer & Winter & Summer \\
\hline \multirow[t]{3}{*}{$P_{\text {net }}$} & $\mathrm{Pf}_{\max }\left(\mu \mathrm{mol} \mathrm{O} \mathrm{O}_{2} \mathrm{~cm}^{-2} \mathrm{~h}^{-1}\right)$ & $0.51 \pm 0.04$ & $0.30 \pm 0.06$ & $0.41 \pm 0.06$ & $0.25 \pm 0.02$ \\
\hline & $T_{\text {opt }}\left({ }^{\circ} \mathrm{C}\right)$ & $24.4 \pm 0.4$ & $27.9 \pm 1.5$ & $21.4 \pm 2.4$ & $22.8 \pm 3.3$ \\
\hline & $T_{\mathrm{br}}\left({ }^{\circ} \mathrm{C}\right)$ & $7.1 \pm 1.7$ & $10.5 \pm 0.8$ & $12.2 \pm 3.5$ & $18.5 \pm 4.7$ \\
\hline$R$ & $Q_{10}$ & $3.4 \pm 1.8$ & $2.7 \pm 1.0$ & $2.1 \pm 0.9$ & $1.6 \pm 0.3$ \\
\hline \multirow[t]{3}{*}{$F_{\mathrm{v}} / F_{\mathrm{m}}$} & $\mathrm{Pf}_{\max }$ (no unit) & $0.62 \pm 0.04$ & $0.72 \pm 0.01$ & $0.58 \pm 0.02$ & $0.67 \pm 0.03$ \\
\hline & $T_{\text {opt }}\left({ }^{\circ} \mathrm{C}\right)$ & $27.6 \pm 1.0$ & $26.0 \pm 0.8$ & $28.0 \pm 2.7$ & $27.7 \pm 0.9$ \\
\hline & $T_{\mathrm{br}}\left({ }^{\circ} \mathrm{C}\right)$ & $28.2 \pm 4.4$ & $30.9 \pm 7.6$ & $51.3 \pm 22.7$ & $30.3 \pm 10.4$ \\
\hline \multirow[t]{3}{*}{$\mathrm{rETR}_{\mathrm{m}}$} & $\mathrm{Pf}_{\max }$ (no unit) & $85.3 \pm 3.1$ & $92.3 \pm 6.9$ & $98.9 \pm 7.5$ & $99.5 \pm 10.8$ \\
\hline & $T_{\mathrm{opt}}\left({ }^{\circ} \mathrm{C}\right)$ & $25.7 \pm 0.5$ & $28.6 \pm 0.3$ & $26.0 \pm 0.6$ & $29.0 \pm 1.0$ \\
\hline & $T_{\mathrm{br}}\left({ }^{\circ} \mathrm{C}\right)$ & $13.2 \pm 2.1$ & $7.6 \pm 0.5$ & $12.5 \pm 0.9$ & $9.8 \pm 1.8$ \\
\hline \multirow[t]{3}{*}{$E_{k}$} & $\mathrm{Pf}_{\max }\left(\mu \mathrm{mol}\right.$ photons $\left.\mathrm{m}^{-2} \mathrm{~s}^{-1}\right)$ & $261.4 \pm 22.4$ & $250.1 \pm 25.4$ & $323.7 \pm 27.1$ & $280.3 \pm 37.5$ \\
\hline & $T_{\text {opt }}\left({ }^{\circ} \mathrm{C}\right)$ & $23.6 \pm 2.5$ & $28.7 \pm 0.4$ & $26.1 \pm 0.5$ & $29.2 \pm 1.0$ \\
\hline & $T_{\mathrm{br}}\left({ }^{\circ} \mathrm{C}\right)$ & $23.6 \pm 7.1$ & $8.3 \pm 1.0$ & $14.1 \pm 1.1$ & $10.3 \pm 1.8$ \\
\hline
\end{tabular}


Table 3 . Welch $t$-tests to detect variability between seasons in the parameter estimates of the thermal performance curves for Acropora valenciennesi and Porites cylindrica. See Table 2 for parameter units and definitions of abbreviations

\begin{tabular}{|c|c|c|c|c|c|c|c|}
\hline \multirow{2}{*}{$\begin{array}{l}\text { Thermal } \\
\text { response }\end{array}$} & \multirow{2}{*}{$\begin{array}{l}\text { Parameter } \\
\text { estimate }\end{array}$} & \multicolumn{3}{|c|}{ A. valenciennesi } & \multicolumn{3}{|c|}{ P. cylindrica } \\
\hline & & $t$ & df & $\mathrm{p}$ & $t$ & df & $\mathrm{p}$ \\
\hline \multirow[t]{3}{*}{$P_{\text {net }}$} & $\mathrm{Pf}_{\max }$ & -7.242 & 8.639 & 0.000 & -5.417 & 4.792 & 0.003 \\
\hline & $T_{\mathrm{opt}}$ & 5.645 & 5.678 & 0.002 & 0.852 & 9.988 & 0.414 \\
\hline & $T_{\mathrm{br}}$ & 4.111 & 5.408 & 0.008 & 2.628 & 9.958 & 0.025 \\
\hline \multirow[t]{3}{*}{$F_{\mathrm{v}} / F_{\mathrm{m}}$} & $\mathrm{Pf}_{\max }$ & 6.033 & 4.492 & 0.003 & 5.756 & 9.942 & 0.000 \\
\hline & $T_{\mathrm{opt}}$ & -2.272 & 7.364 & 0.056 & -0.217 & 4.583 & 0.837 \\
\hline & $T_{\mathrm{br}}$ & 0.733 & 8.199 & 0.484 & -1.928 & 5.216 & 0.109 \\
\hline \multirow[t]{3}{*}{$\mathrm{rETR}_{\mathrm{m}}$} & $\mathrm{Pf}_{\max }$ & 2.208 & 7.167 & 0.062 & 0.113 & 10 & 0.913 \\
\hline & $T_{\text {opt }}$ & 11.159 & 6.351 & 0.000 & 6.463 & 9.562 & 0.000 \\
\hline & $T_{\mathrm{br}}$ & -5.831 & 4.309 & 0.003 & -3.426 & 9.322 & 0.007 \\
\hline \multirow[t]{3}{*}{$E_{k}$} & $\mathrm{Pf}_{\max }$ & -0.784 & 8.948 & 0.453 & -1.954 & 9.814 & 0.080 \\
\hline & $T_{\mathrm{opt}}$ & 4.601 & 4.148 & 0.009 & 7.104 & 9.340 & 0.000 \\
\hline & $T_{\mathrm{br}}$ & -4.802 & 4.121 & 0.008 & -4.666 & 9.842 & 0.001 \\
\hline
\end{tabular}

ture in a similar fashion as $\mathrm{rETR}_{\mathrm{m}}$ with no significant variation in the height of the curve between winter and summer for either species, but a higher $T_{\text {opt }}$ in summer and wider $T_{\mathrm{br}}$ in winter (Table 3).

\subsection{Within-population variability}

Since the objective of this study was to investigate plasticity at species level, data were aggregated across colonies and ignored the withinpopulation (among-colony) variability in thermal performance. However, when non-linear and linear regressions were fitted to data separated by season, species and colony, AIC tests

summer, but there was no change in $T_{\text {opt }}$ and $T_{\mathrm{br}}$ (Table 3). Although some parameter estimates appear higher ( $T_{\mathrm{opt}}$ of $A$. valenciennesi, $T_{\mathrm{br}}$ of $P$. cylindrica) in winter than in summer, the standard error and $95 \%$ confidence intervals around these parameter estimates were large (large error bars, Fig. S3 in the Supplement), caused by large variation in the $T_{\text {opt }}$ and $T_{\text {br }}$ of symbionts within different coral colonies.

The optimal temperature for performance of the $\mathrm{rETR}_{\mathrm{m}}$ was similar for both species in winter (Fig. $2 g, h$ ), and $\sim 2^{\circ} \mathrm{C}$ higher than the environmental temperature. However, in summer, $T_{\text {opt }}$ increased to correspond to the environmental temperature $\left(28.6 \pm 0.3\right.$ and $29.0 \pm 1.0^{\circ} \mathrm{C}$ for $A$. valenciennesi and $P$. cylindrica, respectively). Likewise, both species had equally wide thermal breadths in winter, but this significantly decreased in summer by $>20 \%$ for $P$. cylindrica (from $12.5 \pm 0.9^{\circ} \mathrm{C}$ in winter to $9.8 \pm 1.8^{\circ} \mathrm{C}$ in summer) and $\sim 40 \%$ for $A$. valenciennesi (from $13.2 \pm$ $2.1^{\circ} \mathrm{C}$ in winter to $7.6 \pm 0.5^{\circ} \mathrm{C}$ in summer). Furthermore, the height of the curve did not significantly change between seasons for either species (Table 3). Variation in $\mathrm{rETR}_{\mathrm{m}}$ among species and seasons was consistent regardless of whether $\mathrm{rETR}_{\mathrm{m}}$ was estimated using Eq. (3) or whether it was taken as the value of rETR at the average ambient light intensity at the time of data collection (Fig. S4 in the Supplement).

Lastly, the light saturation coefficient ( $E_{k}$ Fig. 2i,j) in winter was on average $243 \pm 27$ and $282 \pm 48 \mu \mathrm{mol}$ photons $\mathrm{m}^{-2} \mathrm{~s}^{-1}$ for A. valenciennesi and P. cylindrica, respectively. Remarkably, in summer, $E_{k}$ decreased almost 1.3-fold for both species, while the overall light exposure was 2-fold higher in summer than in winter (Fig. S1). In addition, $E_{k}$ varied with tempera- showed that this improved the fit of the model for every response variable (Table S3). This indicates significant variability in the thermal performance of colonies within local populations. Variability in $T_{\text {opt }}$ was particularly large for the holobiont response between $A$. valenciennesi colonies in summer (ranging from 25.8 to $29.5^{\circ} \mathrm{C}$ ), while in winter the magnitude of variation was reduced to $<1^{\circ} \mathrm{C}$ (Fig. 3a). Similarly for $P$. cylindrica (Fig. 3b), the variability in $T_{\text {opt }}$ between colonies for the holobiont response was more than double in summer compared with winter.

\subsection{Chlorophyll concentration}

Chlorophyll concentrations were similar between seasons for A. valenciennesi colonies (Fig. 4a), but were lower in winter for $P$. cylindrica colonies (Fig. 4b; mixed-effects ANOVA with main effect of season, $\left.F_{1,10}=22.47, \mathrm{p}<0.001\right)$. The effect of thermal exposure on the chlorophyll concentration was also not apparent in A. valenciennesi colonies (mixedeffects ANOVA with main effect of treatment, $F_{1,13}=$ 4.64, p > 0.05), but in P. cylindrica, chlorophyll concentrations were lower in colonies exposed to the increased thermal gradient (main effect of treatment, $\left.F_{1,17}=13.81, \mathrm{p}<0.01\right)$. However, this effect was only significant in summer (main effect of treatment on chlorophyll concentration analysed separately for $P$. cylindrica colonies in summer, $F_{1,12}=14.21, \mathrm{p}=$ 0.003). In addition, chlorophyll concentrations were higher in heated $A$. valenciennesi colonies compared with chilled $A$. valenciennesi colonies, whereas the opposite was observed in $P$. cylindrica colonies. 

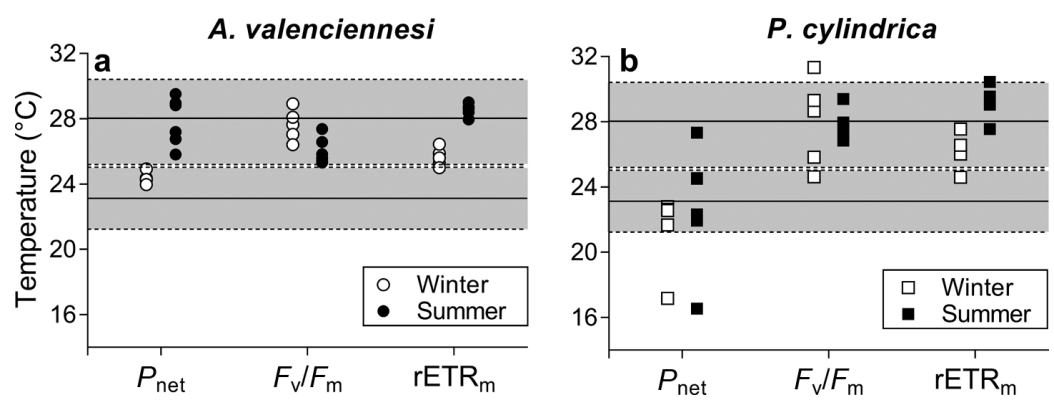

Fig. 3. Variation in optimal temperature ( $\left.T_{\text {opt }}\right)$ between colonies of (a) Acropora valenciennesi and (b) Porites cylindrica during summer and winter for net photosynthesis $\left(P_{\text {net }}\right)$, maximum PSII quantum yield $\left(F_{\mathrm{v}} / F_{\mathrm{m}}\right)$ and maximum electron transport rate $\left(\mathrm{rETR}_{\mathrm{m}}\right)$. Datapoints: mean $T_{\text {opt }}$ derived by non-linear regression of 2 or 4 fragments from the same colony. Horizontal lines: average seawater temperature measured over $90 \mathrm{~d}$ prior to start of winter (1 July-30 August 2015) and summer (25 October 2015-23 January 2016) experiments. Dashed lines: minimum and maximum temperature during those time intervals. Seawater temperature data recorded by in situ data loggers of the Australian Institute of Marine Science around Orpheus Island at $5.8 \mathrm{~m}$ depth (AIMS 2017)

\section{A. valenciennesi}

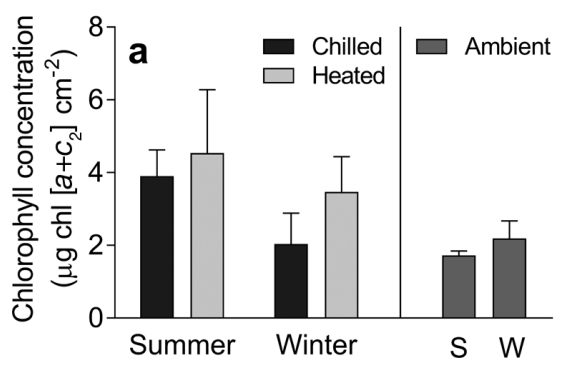

P. cylindrica

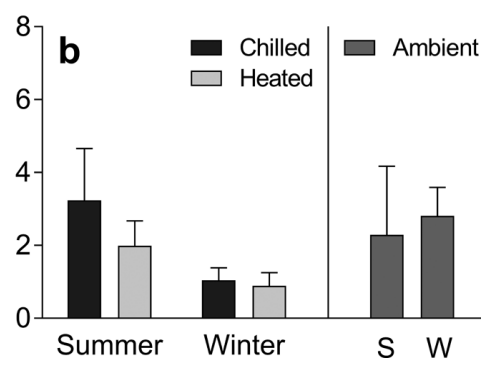

Fig. 4. Chlorophyll concentrations (mean $\pm \mathrm{SD}$ ) of (a) Acropora valenciennesi and (b) Porites cylindrica measured on fragments before (ambient, $\mathrm{n}=5$ ) and after (chilled and heated, $\mathrm{n}=10$ ) completion of the thermal summer and winter experiment. Chilled fragments were exposed to $5^{\circ} \mathrm{C}$ decrease over $10 \mathrm{~d}$ and heated fragments were exposed to $5^{\circ} \mathrm{C}$ increase over $10 \mathrm{~d}$

Lastly, the chlorophyll concentration in fragments at ambient temperature was similar across seasons and between species (2-way ANOVA with season and species as main effects, respectively: $F_{1,20}=3.19, \mathrm{p}=$ 0.09 and $F_{1,20}=1.12, \mathrm{p}=0.30$ ).

\section{DISCUSSION}

This study quantified the seasonal variation in the thermal optimum and thermal breadth of several holobiont and symbiont physiological traits for 2 coral species that differ in their responses to heat stress (bleaching tolerance). Both species were physiologically plastic, but this plasticity was colony- and species-specific at the holobiont level, whereas the symbiont plasticity was limited and uniform across both coral species. At the holobiont level, the species sensitive to heat stress, Acropora valenciennesi, acclimated to changing temperatures primarily by shifting the position of the performance curve. In contrast, the species more tolerant to heat stress, Porites cylindrica, acclimated by altering the performance breadth. However, at the symbiont level, the performance curve only changed through variation in the height of the curve, while the thermal optimum and performance breadth remained unchanged. Furthermore, $T_{\text {opt }}$ of most traits did not correspond to the ambient environmental temperature, but was between the summer and winter temperatures. Lastly, significant within-population variability implied among-genotype variation, which was particularly large for the holobiont traits.

The performance breadth of $P$. Cylindrica colonies was nearly twice as wide as that of $A$. valenciennesi. To our knowledge, this study is the first to identify such differences in thermal acclimation strategies of coral species. A large thermal performance breadth implies that the holobiont physiology is relatively insensitive to changes in temperature. This is consistent with previous studies that reported that $P$. cylindrica is resistant to thermal stress (Visram \& Douglas 2007, Fitt et al. 2009). In contrast, a small thermal performance breadth reflects a sharp peaked thermal sensitivity and indicates that the holobiont performance changes rapidly with temperature. Indeed, Acropora spp. in general, and branching morphologies such as A. valenciennesi in particular, have been frequently reported to rapidly respond to small changes in the temperature of the environment, often with detrimental effects including bleaching-related mortality (e.g. Loya et al. 2001, Hoogenboom et al. 2017). Our study also showed that, in response to seasonal variation in the environmental temperature, A. valenciennesi shifted its thermal optimum for performance and changed the performance breadth, whereas $P$. cylindrica only varied the performance breadth. Such 
differences in thermal strategy despite sharing an identical thermal history supports the fact that species do not perceive, or respond to, their thermal environment the same way (Angilletta et al. 2006).

There are several potential explanations for the observed variation in the thermal strategy between our coral species. First, it could simply be due to genetic divergence among species or because the corals harboured different Symbiodiniaceae species. Variation in the symbiont population among the coral species may confer different functional traits to the holobiont. For instance, Cladocopium C15 (associated with P. cylindrica; Fisher et al. 2012) is known to be thermally tolerant and may facilitate holobiont performance across a wide range of temperatures. In contrast, most acroporid species, including A. valenciennesi, host C1/C3, which is a generalist symbiont rarely found in thermally tolerant holobionts. Instead, many acroporid species host multiple subdominant symbiont types with different functional traits (van Oppen et al. 2001, Stat et al. 2008), which may result in reversible thermal optima rather than increased thermal breadth. Second, variation in thermal strategy between the species could be related to the spatial distribution of the sampled colonies within local reef microhabitats and the generation time of the species. P. cylindrica is typically abundant on the shallow reef flat and/or reef crest (Madin et al. 2016), which experience a greater range of temperatures (e.g. diel and tidal) than nearby deeper reefs. In contrast, $A$. valenciennesi is found more on the reef slope (Madin et al. 2016), where the thermal environment is typically more stable. Consequently, P. cylindrica may have adapted more of a thermal generalist strategy (i.e. wide performance breadth) to match the larger range of temperatures experienced by colonies over their lifecycle than experienced by $A$. valenciennesi. Further study of thermal acclimation strategies for corals related to the small-scale spatial distribution is required to test this hypothesis. Lastly, several physiological and metabolic mechanisms may have varied between the 2 species that could have influenced the thermal acclimation strategy. Variation in species metabolic rates could be due to differences in the energy allocation between tissue versus skeleton required by different colony morphology (Anthony et al. 2002), which could drive different thermal strategies (e.g. Gates \& Edmunds 1999).

Respiration and net photosynthesis rates were lower in summer than in winter, consistent with decreased light saturation levels despite higher overall light exposure. These shifts are contradictory to previous studies that showed higher productivity in summer related to higher summer growth and calcification rates (e.g. Scheufen et al. 2017b), as well as higher $E_{k}$ values related to higher PAR (Anthony \& Hoegh-Guldberg 2003). Likewise, fluctuations in chlorophyll and symbiont concentrations are commonly observed among seasons (Ulstrup et al. 2008, Winters et al. 2009), yet our study showed similar chlorophyll concentrations between summer and winter at the start of each thermal experiment (ambient treatment, Fig. 4). These inconsistencies cannot be attributed to photoacclimation during the $10 \mathrm{~d}$ of the thermal experiment, as the irradiance in the holding and experimental tanks was similar. However, the resampling of fragments in November/December for the summer thermal experiment may have introduced variation in the photoacclimation states of the fragments compared to those measured during the winter thermal experiment. For instance, variation in host pigmentation (Dove et al. 2008, Scheufen et al. 2017a) or host macrostructure (Wangpraseurt et al. 2014) can alter the light microenvironment and may have lowered the $E_{k}$ value during the summer thermal experiment as well as the net photosynthesis rate. Additionally, there was a prolonged period of heat stress prior to the start of the summer experiment throughout the Great Barrier Reef that severely impacted the northern section and to a lesser extent the central third, including the Palm Islands (Hughes et al. 2017). Although bleaching was not observed during the summer thermal experiment, and $F_{\mathrm{v}} / F_{\mathrm{m}}$ remained high, prolonged high temperatures accompanied by high summer irradiance may have impacted several physiological pathways in the holobiont and symbiont (Fitt et al. 2001). In line with this, increased protein repair rates to avoid photodamage (Feder \& Hofmann 1999) may have impeded thermal acclimation of the photosynthetic performance. Angilletta et al. (2003) identified several tradeoffs that constrain performance curves due to mechanisms that underlie the expression of phenotypes. The allocation tradeoff dictates that increased performance of one trait at a certain temperature occurs at the expense of decreased performance of another trait at that temperature. Hence, despite enhanced photosynthetic capacity in summer at the symbiont level, photosynthetic performance at the holobiont level may have been compromised due to costs associated with thermal stress.

The Gaussian curve is frequently applied to model the relationship between temperature and performance in the field of thermal biology (Angilletta 2006). However, in the present study, linear 
regression provided a better fit to model the respiration performance, even though linear approximations should be avoided since they fundamentally differ from the dynamics of the biological and physiological processes that underlie thermal performance (Bulte \& Blouin-Demers 2006). Nevertheless, a linear relationship between coral respiration and temperature is reported previously by Coles \& Jokiel (1977). The most likely explanation for this is that the performance curve for respiration is highly asymmetrical (skewed to the left), with the optimum (i.e. temperature at which the respiration rate is highest) very close to the upper critical threshold temperature. Hence, we expect that exposure of corals to higher (more extreme) temperatures than the $\pm 5^{\circ} \mathrm{C}$ range used in this study would show a rapid decline of the respiration performance. In a previous study on the metabolic rate of the killifish Fundulus heteroclitus, Healy \& Schulte (2012) were also unable to capture the falling phase of the curve because the organism's critical thermal maximum was at temperatures slightly higher than those measured. In addition, interpretation of thermal optima for respiration rates in corals is complex, due to multiple, competing energy-requiring processes. First, respiration rates are partitioned between animal host and algal symbiont, and positive correlations are found between symbiont density and host aerobic capacity (Hawkins et al. 2016). Second, changes in the respiration rate may be due to changes in the energy expenditure for calcification (Al-Horani et al. 2003) which would be beneficial for colony growth, but can also reflect increases in the metabolic rates of the host and symbiont in response to stress. Increased respiration rates at elevated temperatures have been demonstrated for numerous organisms, including terrestrial plants (Berry \& Bjorkman 1980), anemones (Goulet et al. 2005) and corals (Coles \& Jokiel 1977), and have been attributed to increased oxygen consumption at the mitochondrial level (Pörtner 2002, Schulte 2015). Furthermore, the timescale at which the thermal response is measured can strongly influence the shape of the TPC (Schulte et al. 2011). We aimed to capture the acute response to thermal change without distressing the coral, and therefore the ramping rate did not exceed $0.5^{\circ} \mathrm{C} \mathrm{d} \mathrm{d}^{-1}$. However, it is possible that the TPC for respiration would be of a different shape if a different ramping rate was used.

Results showed that coral thermal acclimation rarely resulted in a perfect match between the thermal optima and average environmental temperatures. This suggests that, as predicted by Gabriel
(2005), the variability of the thermal environment, the time required for adjusting the physiology and the costs associated with acclimation constrain acclimation rates and magnitudes. At our study location, the mean environmental temperature calculated over 2 wk prior to the start of the experiment was $29^{\circ} \mathrm{C}$ in summer and $24^{\circ} \mathrm{C}$ in winter, but this mean varied by $>1^{\circ} \mathrm{C}$ when calculated over the $4 \mathrm{wk}$ period prior to the start of the experiment. Such rapid fluctuations indicate that the environment is less predictable, which reduces the benefits of acclimation. This is especially true for holobiont acclimation that involves restructuring or synthesizing of proteins and pigments (Black et al. 1995, Fitt et al. 2009), uptake or expulsion of symbionts (Hoegh-Guldberg \& Smith 1989, Muscatine et al. 1991, Fitt et al. 2009), and changes in mitochondrial density (Pörtner 2002). Consequently, holobiont acclimation is likely to be more time-consuming and energetically costly than acclimation of the photosynthetic apparatus at the symbiont level, which may explain why the only perfectly acclimated trait to summer temperature was the electron transport rate.

Lastly, the within-population variability of $T_{\text {opt }}$ showed that thermal acclimation varied between coral colonies. This variation cannot be attributed to differences in the photoacclimatory state of the mother colonies, as fragments were acclimated for several months to the tank conditions to minimize potential differences in the light field caused by the macrostructure of the mother colonies. Therefore, the within-population variability is most likely caused by genetic variation in both thermal tolerance and thermal plasticity for both of the coral species investigated in this study. Such variation could be related to differences in the 'age' of the sampled coral colonies that could drive a divergence between the current environment and the selective environment at the time of development (De Jong 1999). Irreversible acclimation of some phenotypic traits might have been established during the early developmental stages of the coral larvae and juveniles, and this could constrain the thermal performance and plasticity of adult colonies. Although further research is needed to determine the mechanisms underlying differences in thermal acclimation among colonies, our results indicate that such differences are primarily driven by the coral host, as the thermal performance of Symbiodinium living within the 2 coral species was less plastic than that of the coral hosts. To confirm this hypothesis, further research is also required that measures the characteristics of the host and symbiont alone (e.g. Hawkins et al. 2016), since the holo- 
biont performance in our study is driven by the Symbiodinium as well.

The unprecedented global coral bleaching event of 2017 (Hughes et al. 2017) has highlighted the need to understand the capacity of corals to acclimate to elevated temperatures. Current models that project coral population dynamics in climate change scenarios (e.g. Hoegh-Guldberg et al. 2007) do not incorporate the reversible acclimation capacity of corals, or their performance at sublethal temperatures, while both processes influence population fitness and coral survival. The present study showed that the thermally sensitive $A$. valenciennesi maximized performance between seasons by shifting the thermal optimum, whereas the thermally tolerant $P$. cylindrica maintained performance through widening the performance breadth. Such differences in thermal strategy imply that during summer warming, A. valenciennesi is likely to maintain high performance until a threshold temperature, after which performance will decline rapidly. In contrast, the performance of $P$. cylindrica is less affected by temperature change and therefore will decline less dramatically at summer extremes. Additionally, the symbiont response to seasonal warming and cooling was generally consistent among the study species, and the electron transport rate was perfectly acclimated to the ambient temperature in both seasons. These results suggest that the capacity for physiological acclimation of the coral host, rather than the symbionts, will limit coral performance as ocean temperatures increase in the future.

Acknowledgements. We thank the staff at Orpheus Island Research Station for their help and support with the fieldwork and experiments. Corals were collected under Great Barrier Reef Marine Park Authority permits G12/35052.1, G14/36788.1 and G15/38232.1. This research was funded by the Australian Research Council grant to the ARC Centre of Excellence for Coral Reef Studies, and by James Cook University.

\section{LITERATURE CITED}

Aichelman HE, Zimmerman RC, Barshis DJ (2019) Adaptive signatures in thermal performance of the temperate coral Astrangia poculata. J Exp Biol 222:jeb189225

AIMS (Australian Institute of Marine Science) (2017) Sea Temperature Observing System. http://maps.aims.gov. au (accessed 19 April 2017)

Al-Horani F, Al-Moghrabi S, De Beer D (2003) The mechanism of calcification and its relation to photosynthesis and respiration in the scleractinian coral Galaxea fascicularis. Mar Biol 142:419-426

Angilletta MJ (2006) Estimating and comparing thermal performance curves. J Therm Biol 31:541-545
Angilletta MJ (2009) Thermal adaptation: a theoretical and empirical synthesis. Oxford University Press, New York, NY

Angilletta MJ, Wilson RS, Navas CA, James RS (2003) Tradeoffs and the evolution of thermal reaction norms. Trends Ecol Evol 18:234-240

*Angilletta MJ, Bennett AF, Guderley H, Navas CA, Seebacher F, Wilson RS (2006) Coadaptation: a unifying principle in evolutionary thermal biology. Physiol Biochem Zool 79:282-294

Anthony KR, Hoegh-Guldberg O (2003) Kinetics of photoacclimation in corals. Oecologia 134:23-31

Anthony KR, Connolly SR, Willis BL (2002) Comparative analysis of energy allocation to tissue and skeletal growth in corals. Limnol Oceanogr 47:1417-1429

* Bauwens D, Garland T, Castilla AM, Van Damme R (1995) Evolution of sprint speed in lacertid lizards: morphological, physiological, and behavioral covariation. Evolution 49:848-863

* Berkelmans R, Van Oppen MJ (2006) The role of zooxanthellae in the thermal tolerance of corals: a 'nugget of hope' for coral reefs in an era of climate change. Proc $\mathrm{R}$ Soc B 273:2305-2312

Berkelmans R, Willis B (1999) Seasonal and local spatial patterns in the upper thermal limits of corals on the inshore Central Great Barrier Reef. Coral Reefs 18:219-228

* Berry J, Bjorkman O (1980) Photosynthetic response and adaptation to temperature in higher plants. Annu Rev Plant Physiol 31:491-543

* Black NA, Voellmy R, Szmant AM (1995) Heat shock protein induction in Montastraea faveolata and Aiptasia pallida exposed to elevated temperatures. Biol Bull 188:234-240

Brown BE (1997) Coral bleaching: causes and consequences. Coral Reefs 16:S129-S138

Bulte G, Blouin-Demers G (2006) Cautionary notes on the descriptive analysis of performance curves in reptiles. J Therm Biol 31:287-291

* Coles SL, Brown BE (2003) Coral bleaching-capacity for acclimatization and adaptation. Adv Mar Biol 46: 183-223

Coles SL, Jokiel PL (1977) Effects of temperature on photosynthesis and respiration in hermatypic corals. Mar Biol 43:209-216

Csaszar NB, Ralph PJ, Frankham R, Berkelmans R, van Oppen MJ (2010) Estimating the potential for adaptation of corals to climate warming. PLOS ONE 5:e9751

* De Jong G (1999) Unpredictable selection in a structured population leads to local genetic differentiation in evolved reaction norms. J Evol Biol 12:839-851

* Dove SG, Lovell C, Fine M, Deckenback J, Hoegh Guldberg O, Iglesias-Prieto R, Anthony KR (2008) Host pigments: potential facilitators of photosynthesis in coral symbioses. Plant Cell Environ 31:1523-1533

Feder ME, Hofmann GE (1999) Heat-shock proteins, molecular chaperones, and the stress response: evolutionary and ecological physiology. Annu Rev Physiol 61:243-282

Fisher P, Malme M, Dove S (2012) The effect of temperature stress on coral-Symbiodinium associations containing distinct symbiont types. Coral Reefs 31:473-485

Fitt WK, Brown BE, Warner ME, Dunne RP (2001) Coral bleaching: interpretation of thermal tolerance limits and thermal thresholds in tropical corals. Coral Reefs 20: $51-65$

F Fitt WK, Gates RD, Hoegh-Guldberg O, Bythell JC and others (2009) Response of two species of Indo-Pacific corals, 
Porites cylindrica and Stylophora pistillata, to short-term thermal stress: The host does matter in determining the tolerance of corals to bleaching. J Exp Mar Biol Ecol 373: 102-110

Gabriel W (2005) How stress selects for reversible phenotypic plasticity. J Evol Biol 18:873-883

Gates RD, Edmunds PJ (1999) The physiological mechanisms of acclimatization in tropical reef corals. Am Zool 39:30-43

Goulet TL, Cook CB, Goulet D (2005) Effect of short term exposure to elevated temperatures and light levels on photosynthesis of different host symbiont combinations in the Aiptasia pallida/Symbiodinium symbiosis. Limnol Oceanogr 50:1490-1498

*Hawkins TD, Hagemeyer JCG, Hoadley KD, Marsh AG, Warner ME (2016) Partitioning of respiration in an animal-algal symbiosis: implications for different aerobic capacity between Symbiodinium spp. Front Physiol 7:128

Healy TM, Schulte PM (2012) Thermal acclimation is not necessary to maintain a wide thermal breadth of aerobic scope in the common killifish (Fundulus heteroclitus). Physiol Biochem Zool 85:107-119

* Hoegh-Guldberg O, Jones RJ (1999) Photoinhibition and photoprotection in symbiotic dinoflagellates from reefbuilding corals. Mar Ecol Prog Ser 183:73-86

Hoegh-Guldberg O, Smith GJ (1989) The effect of sudden changes in temperature, light and salinity on the population density and export of zooxanthellae from the reef corals Stylophora pistillata Esper and Seriatopora hystrix Dana. J Exp Mar Biol Ecol 129:279-303

*Hoegh-Guldberg O, Mumby PJ, Hooten AJ, Steneck RS and others (2007) Coral reefs under rapid climate change and ocean acidification. Science 318:1737-1742

Hoogenboom MO, Frank GE, Chase TJ, Jurriaans S and others (2017) Environmental drivers of variation in bleaching severity of Acropora species during an extreme thermal anomaly. Front Mar Sci 4:376

Howells E, Beltran V, Larsen N, Bay L, Willis B, Van Oppen M (2012) Coral thermal tolerance shaped by local adaptation of photosymbionts. Nat Clim Change 2:116-120

* Howells EJ, Berkelmans R, van Oppen MJ, Willis BL, Bay LK (2013) Historical thermal regimes define limits to coral acclimatization. Ecology 94:1078-1088

*Howells EJ, Abrego D, Meyer E, Kirk NL, Burt JA (2016) Host adaptation and unexpected symbiont partners enable reef building corals to tolerate extreme temperatures. Glob Change Biol 22:2702-2714

Huey RB, Stevenson R (1979) Integrating thermal physiology and ecology of ectotherms: a discussion of approaches. Am Zool 19:357-366

*ैHughes TP, Kerry JT, Álvarez-Noriega M, Álvarez-Romero JG and others (2017) Global warming and recurrent mass bleaching of corals. Nature 543:373-377

* Jeffrey SW, Humphrey G (1975) New spectrophotometric equations for determining chlorophylls $a, b, c_{1}$ and $c_{2}$ in higher plants, algae and natural phytoplankton. Biochem Physiol Pflanz 167:191-194

Jokiel P, Coles S (1990) Response of Hawaiian and other Indo-Pacific reef corals to elevated temperature. Coral Reefs 8:155-162

Jurriaans S, Hoogenboom M (2019) Thermal performance of scleractinian corals along a latitudinal gradient on the Great Barrier Reef. Philos Trans R Soc B 374:20180546

* LaJeunesse TC, Loh WK, Van Woesik R, Hoegh Guldberg
O, Schmidt GW, Fitt WK (2003) Low symbiont diversity in southern Great Barrier Reef corals relative to those of the Caribbean. Limnol Oceanogr 48:2046-2054

* LaJeunesse TC, Parkinson JE, Gabrielson PW, Jeong HJ, Reimer JD, Voolstra CR, Santos SR (2018) Systematic revision of Symbiodiniaceae highlights the antiquity and diversity of coral endosymbionts. Curr Biol 28:2570-2580

* Logan CA, Dunne JP, Eakin CM, Donner SD (2014) Incorporating adaptive responses into future projections of coral bleaching. Glob Change Biol 20:125-139

Koya Y, Sakai K, Yamazato K, Nakano Y, Sambali H, van Woesik R (2001) Coral bleaching: the winners and the losers. Ecol Lett 4:122-131

*Madin JS, Anderson KD, Andreasen MH, Bridge TC and others (2016) The Coral Trait Database, a curated database of trait information for coral species from the global oceans. Sci Data 3:160017

Muscatine L, Grossman D, Doino J (1991) Release of symbiotic algae by tropical sea anemones and corals after cold shock. Mar Ecol Prog Ser 77:233-243

Nitschke MR, Gardner SG, Goyen S, Fujise L, Camp EF, Ralph PJ, Suggett DJ (2018) Utility of photochemical traits as diagnostics of thermal tolerance amongst Great Barrier Reef corals. Front Mar Sci 5:45

* Oliver T, Palumbi S (2011) Do fluctuating temperature environments elevate coral thermal tolerance? Coral Reefs 30:429-440

Platt T, Gallegos CL, Harrison WG (1980) Photoinhibition of photosynthesis in natural assemblages of marine phytoplankton. J Mar Res 38:687-701

Pörtner HO (2002) Climate variations and the physiological basis of temperature dependent biogeography: systemic to molecular hierarchy of thermal tolerance in animals. Comp Biochem Physiol A 132:739-761

Pörtner HO, Karl DM, Boyd PW, Cheung W and others (2014) Ocean systems. In: Field CB, Barros VR, Dokken DJ, Mach KJ and others (eds) Climate change 2014: impacts, adaptation, and vulnerability. Part A: Global and sectoral aspects. Contribution of Working Group II to the Fifth Assessment Report of the Intergovernmental Panel on Climate Change. Cambridge University Press, Cambridge, p 411-484

* Ralph PJ, Gademann R (2005) Rapid light curves: a powerful tool to assess photosynthetic activity. Aquat Bot 82: 222-237

Kobison JD, Warner ME (2006) Differential impacts of photoacclimation and thermal stress on the photobiology of four different phylotypes of Symbiodinium (Pyrrhophyta). Jpn J Phycol 42:568-579

* Rodolfo Metalpa R, Hoogenboom MO, Rottier C, Ramos Esplá A, Baker AC, Fine $M$, Ferrier Pagès C (2014) Thermally tolerant corals have limited capacity to acclimatize to future warming. Glob Change Biol 20: 3036-3049

* Sawall Y, Al-Sofyani A, Hohn S, Banguera-Hinestroza E, Voolstra CR, Wahl M (2015) Extensive phenotypic plasticity of a Red Sea coral over a strong latitudinal temperature gradient suggests limited acclimatization potential to warming. Sci Rep 5:8940

* Scheufen T, Iglesias-Prieto R, Enríquez S (2017a) Changes in the number of symbionts and Symbiodinium cell pigmentation modulate differentially coral light absorption and photosynthetic performance. Front Mar Sci 4:309

* Scheufen T, Krämer WE, Iglesias-Prieto R, Enríquez S (2017b) Seasonal variation modulates coral sensibility to 
heat-stress and explains annual changes in coral productivity. Sci Rep 7:4937

Schreiber U (2004) Pulse-amplitude-modulation (PAM) fluorometry and saturation pulse method: an overview. In: Papageorgiou GC, Govindjee (eds) Chlorophyll a fluorescence. Springer, Dordrecht, p 279-319

Schulte PM (2015) The effects of temperature on aerobic metabolism: towards a mechanistic understanding of the responses of ectotherms to a changing environment. J Exp Biol 218:1856-1866

Schulte PM, Healy TM, Fangue NA (2011) Thermal performance curves, phenotypic plasticity, and the time scales of temperature exposure. Integr Comp Biol 51: 691-702

Silverstein RN, Cunning R, Baker AC (2015) Change in algal symbiont communities after bleaching, not prior heat exposure, increases heat tolerance of reef corals. Glob Change Biol 21:236-249

Stat M, Morris E, Gates RD (2008) Functional diversity in coral-dinoflagellate symbiosis. Proc Natl Acad Sci USA 105:9256-9261

Tagliarolo M, McQuaid CD (2015) Sub-lethal and sub-specific temperature effects are better predictors of mussel distribution than thermal tolerance. Mar Ecol Prog Ser 535:145-159

Ulstrup KE, Hill R, van Oppen MJH, Larkum AWD, Ralph PJ (2008) Seasonal variation in the photo-physiology of homogeneous and heterogeneous Symbiodinium consortia in two scleractinian corals. Mar Ecol Prog Ser 361: 139-150

van Oppen MJ, Palstra FP, Piquet AMT, Miller DJ (2001) Patterns of coral-dinoflagellate associations in Acropora:

Editorial responsibility: Inna Sokolova,

Rostock, Germany significance of local availability and physiology of Symbiodinium strains and host-symbiont selectivity. Proc R Soc B 268:1759-1767

*Veal C, Carmi M, Fine M, Hoegh-Guldberg O (2010) Increasing the accuracy of surface area estimation using single wax dipping of coral fragments. Coral Reefs 29: 893-897

Visram S, Douglas AE (2007) Resilience and acclimation to bleaching stressors in the scleractinian coral Porites cylindrica. J Exp Mar Biol Ecol 349:35-44

*Wangpraseurt D, Polerecky L, Larkum AW, Ralph PJ, Nielsen DA, Pernice M, Kühl M (2014) The in situ light microenvironment of corals. Limnol Oceanogr 59: 917-926

Warner M, Chilcoat G, McFarland F, Fitt W (2002) Seasonal fluctuations in the photosynthetic capacity of photosystem II in symbiotic dinoflagellates in the Caribbean reefbuilding coral Montastraea. Mar Biol 141:31-38

Whitman DW, Agrawal AA (2009) What is phenotypic plasticity and why is it important? In: Whitman DW, Ananthakrishnan TN (eds) Phenotypic plasticity of insects: mechanisms and consequences. Science Publishers, Enfield, NH, p 1-63

Wilson RS (2001) Geographic variation in thermal sensitivity of jumping performance in the frog Limnodynastes peronii. J Exp Biol 204:4227-4236

*Winters G, Beer S, Zvi BB, Brickner I, Loya Y (2009) Spatial and temporal photoacclimation of Stylophora pistillata: zooxanthella size, pigmentation, location and clade. Mar Ecol Prog Ser 384:107-119

Withers P (1992) Comparative animal physiology. Saunders College Publishing, Fort Worth, TX

Submitted: January 15, 2018; Accepted: November 19, 2019

Proofs received from author(s): January 17, 2020 